\title{
No evidence for adaptive micro-evolution to a decrease in phosphorus-loading of a Daphnia population inhabiting a pre-alpine lake
}

\author{
Piet Spaak* \& Barbara Keller \\ Department of Limnology, EAWAG, Überlandstrasse 133, Postfach 611, 8600 Dübendorf, Switzerland \\ (*Author for correspondence: Tel.: +41-1-823-5617, Fax: +41-1-823-5315,E-mail: spaak@eawag.ch)
}

Key words: hybrid, coexistence, sexual reproduction, Daphnia, diapausing egg, micro-evolution

\begin{abstract}
Many polluted lakes in Europe are being restored and phosphorus concentrations have dropped dramatically in these lakes. We studied the genetic structure of Daphnia galeata over the past 30 years in Lake Greifensee, Switzerland, a period during which the phosphorus concentration in the lake reduced dramatically. Distinct genotypes of $D$. galeata were hatched from diapausing eggs extracted from six different time horizons in dated sediments. We compared juvenile growth, size and egg production of D. galeata reared on high-P and low-P algae to investigate whether Daphnia have evolved to grow better on phosphorus-limited algae. Our results indicate that life histories of $D$. galeata differed significantly between both food types. We also found significant clone effects for size and egg number. But we found no significant interaction between the depth from which the clones were selected and food quality. This means that we found no evidence for adaptive micro-evolution in response to $\mathrm{P}$ reduction in the lake. We discuss our results in relation to other studies that found evidence for adaptive micro-evolution in comparable time frames.
\end{abstract}

\section{Introduction}

Remains of cladocera have been proven to be very useful for paleolimnological studies (Frey, 1969, 1974). Analyzing zooplankton remains allows a planktonic lake-community up to ten-thousand of years old to be reconstructed (Duigan \& Birks, 2000; Jeppesen et al., 2001). Also changes in the species composition, their morphology or possible hybridization events can be documented, as was shown by Hofmann (1991, 1998). In this type of study, remains such as mucrons, postabdominal claws and resting eggs are used. Recently, however, researchers started to analyze diapausing eggs as living remains, trying to hatch them (Hairston et al., 1995; Hairston \& Cáceres, 1996) or to study their genetic make-up by directly genotyping the eggs or their remains (Duffy et al., 2000; Limburg \& Weider, 2002). Analogous to seed banks in terrestrial ecology, deposits of diapausing eggs are called egg banks (De Stasio, 1989).

Analyzing diapausing eggs indirectly or directly (by genotyping the hatched individuals) allows the study of genetic changes in a plankton population over many decades. Several studies using Daphnia, which hatched from lake sediments, have shown that the genetic composition of the population changed over time (Weider et al., 1997; Jankowski, 2002). Others directly analyzed the resting eggs (Duffy et al., 2000; Cousyn et al., 2001; Limburg \& Weider, 2002) using molecular techniques (e.g. microsatellites or MtDNA-sequencing), and produced comparable results. The advantage of directly genotyping eggs is that eggs that do not hatch can also be analyzed. This allows the study 
of past genetic changes over a much longer time frame.

Weider et al. (1997) found a correlation between genetic changes in the D. galeata population of Lake Constance and the reduction in phosphorus concentration of this lake over the past 40 years. In a subsequent study, Hairston et al. $(1999,2001)$ showed that clones that hatched from different sediment layers reacted differently to cyanobacteria, indicating that rapid genetic changes had occurred.

Using clones that hatched from sediment layers that are up to several decades old provides a unique opportunity to directly test specific evolutionary hypotheses. The reaction of 'old' and 'recent' clones can be compared in laboratory experiments, testing how they perform under 'recent' or 'old' conditions. In a recent study, Cousyn et al. (2001) used this approach and showed that evolution can operate very fast. They found that a Daphnia magna population showed strong genetic changes in phototactic behaviour after ten years, and could relate these changes to changes in fish predation pressure.

Many deep pre-alpine lakes received a high input of nutrients and became hypertrophic in the 1960 s and 1970s. Since then they have gone through a process of oligotrophication (Bloesch et al., 1997). In spite of this, many of them are still classified as eutrophic (Ruggiu et al., 1998; van der Molen et al., 1998). Eutrophic conditions have fundamentally changed the biotic and abiotic conditions in these pre-alpine lakes. For example, the hypolimnion of deep lakes became anoxic in summer, leaving a reduced stratum for plankton and fish. The oligotrophication of lakes changed the $\mathrm{C}: \mathrm{P}$ ratio in those lakes, resulting in a change in quality of the algae as food for the zooplankton. P-limited algae are known to be suboptimal food for zooplankton (Sterner et al., 1993). Several studies showed experimentally how high $\mathrm{C}: \mathrm{P}$ ratios change the life histories of Daphnia (Boersma, 2000; Plath \& Boersma, 2001). The goal of our study was to verify whether the fast adaptive reaction of Daphnia to changes in fish predation (Cousyn et al., 2001) or to the presence of cyanobacteria (Hairston et al., 1999) can also be found in their response to food with different $\mathrm{C}: \mathrm{P}$ ratios.

In the present study, we investigate how Daphnia clones that hatched out of different sed- iment layers (up to 30 years old) from Lake Greifensee (Switzerland) perform under laboratory conditions to food (the green algae Scenedesmus obliquus) cultured in P-rich and P-limited conditions. We hypothesized that Daphnia fed with P-limited algae would show smaller clutch sizes and a lower intrinsic rate of increase compared to Daphnia fed with algae grown under high $\mathrm{P}$ conditions. However, under the hypothesis of adaptive evolution, we also expected that Daphnia clones hatched from deeper sediment layers, would do worse under P-limited conditions than Daphnia clones that hatched from more recently produced ephippia. In other words, we expected crossing reaction norms for performance on high and low C:P ratio's, between 'older' and 'younger' clones.

\section{Study site}

Lake Greifensee (Switzerland) is a highly eutrophic pre-alpine lake with a surface area of $8.5 \mathrm{~km}^{2}$ and a volume of $150 \times 10^{6} \mathrm{~m}^{3}$. Its average depth is $17.7 \mathrm{~m}$, with a maximum depth of $33 \mathrm{~m}$. Total phosphorus levels in the lake in February 2000 were less then $70 \mu \mathrm{g} 1 .^{-1}$ and have declined sharply during the last 20 years (Bürgi et al., 2003). Two rivers (Aa-Bach, Möchaltdorfer-Aa) flow into the lake, while one lake outlet (Glatt) drains the system. Only the larger Aa-Bach seems to create a noticeable flow-through towards the lake outlet (Keller et al., 2002). The first major step in the eutrophication of the lake started in the beginning of the last century (Guyer, 1910; Mühlethaler et al., 1993). After the peak of eutrophication in $1973\left(\mathrm{P}_{\text {tot February }}=535 \mu \mathrm{g}^{-1}\right)$, restoration measures were started. Since then, $\mathrm{P}_{\text {tot }}$ values have

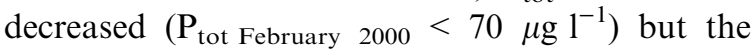
lake is still eutrophic (Mühlethaler et al., 1993).

\section{Materials and methods}

Daphnia clones from the Lake Greifensee sediment

Two species of Daphnia, D. galeata and D. hyalina, coexist in Lake Greifensee, together with their interspecific hybrid (Spaak et al., 2001). There is, however, evidence that the $D$. hyalina genotypes 
actually are backcrosses or $\mathrm{F}_{2}$ hybrids (Spaak et al., 2001). To explore evolutionary changes in life history characteristics, it was necessary to obtain genotypes from different time periods in the past. D. galeata overwhelmingly dominated the hatchling pool from the diapausing eggs isolated from the lake sediment. No D. hyalina hatchlings were obtained, and only a small number of hatchlings (10 out of 118 , B. Keller, unpublished) were $D$. galeata $x$ hyalina hybrids. For this reason, our study is restricted solely to $D$. galeata.

The D. galeata clones were collected as diapausing eggs from two sediment cores taken at the deepest part of the lake (33 m deep) in 1999 (for details see Keller et al., 2002). Since all clones hatched from sexually produced ephippia, they are genetically distinct clones by definition. Sediments were dated by counting annual laminations and confirmed by measurements of ${ }^{137} \mathrm{Cs}$-dating in a parallel core (Keller et al., 2002). The presence of annual layering (varves) within these sediments shows that little or no sediment mixing (e.g. by bioturbation) has occurred in the sediments sampled. The core was sliced at $1.4 \mathrm{~cm}$ intervals and Daphnia ephippia were isolated by sieving. As each slice included roughly 3-5 annual laminations, the age of the eggs can be determined only to this resolution. Ephippa were transferred to cell culture plates with freshly filtered lake water, and exposed to permanent light at $12{ }^{\circ} \mathrm{C}$. The plates were checked daily for hatchlings. Each Daphnia that hatched was cultured individually to establish a parthenogenetic isoclonal line, and was cultured in the laboratory until the experiments were preformed. The clones were screened for genetic variation, to determine their taxon, at two polymorphic allozyme loci using the methods of
Hebert \& Beaton (1989). Aldehyde oxidase (Ao, Enzyme Commission number (EC) 1.2.3.1) and Asparate amino transferase (Aat, EC 2.6.1.1) were scored for each clone. Aat and Ao contain species specific alleles (Wolf \& Mort, 1986; Gießler, 1997). Twenty clones of $D$. galeata from five sedimentage categories and four clones that hatched from recently produced ephippia (Table 1) were tested for their reaction to a diet of P-limited and $\mathrm{P}$ unlimited algae.

\section{Flow through experiment with P-limited and $P$-unlimited food}

We tested 24 D. galeata clones (Table 1) in a flow through system, using Lake Greifensee water as the culture medium. P-content of Lake Greifensee water is low $\left(10 \mu \mathrm{g}^{-1}\right)$ during spring. The animals were grown at $20^{\circ} \mathrm{C}$ in filtered $(0.45 \mu \mathrm{m})$ and aerated lake water. The mothers and grandmothers of the experimental animals were kept with a maximum of five individuals in glass vessels of $200 \mathrm{ml}$ at a 16:8 h light cycle. Water was changed daily. Mothers and grandmothers received chemostat-grown algae (Scenedesmus obliquus) as food at a final carbon concentration of $1 \mathrm{mg} \mathrm{l}^{-1}$. The experiment was conducted in a flow-through set-up in $150 \mathrm{ml}$ Perspex cylinders closed with plankton gauze (mesh size $150 \mu \mathrm{m}$ ), with an exchange rate of $3.5 \mathrm{day}^{-1}$. Cylinders were maintained in a water bath in a climatized room at $20{ }^{\circ} \mathrm{C}$. The food media in the reservoir bottles were stirred continuously, kept in the dark and renewed daily.

The performance of each clone on the two types of food was measured as somatic juvenile

Table 1. Origin of the clones used in the experiment

\begin{tabular}{lllllll}
\hline Depth code & Sediment depth & Year & \multicolumn{4}{l}{ Experimental Daphnia clones } \\
\hline 0 & Water column & 2000 & FL18 & FL30 & FL35 & FL36 \\
2 & $1.4-2.8$ & $91-95$ & A11 & A12 & A70 & A100 \\
3 & $2.8-4.2$ & $87-91$ & A57 & B13 & B17 & B44 \\
4 & $4.2-5.6$ & $83-87$ & B39 & B40 & B46 & B58 \\
5 & $5.6-7.0$ & $77-83$ & B50 & B75 & B76 & B97 \\
6 & $7.0-8.4$ & $72-77$ & B57 & B67 & B79 & B85 \\
\hline
\end{tabular}

Clones from 'depth 0' were hatched from 'freshly' produced floating ephippia, collected 25 May 2000 in Lake Greifensee. The other clones were hatched from two cores taken on 4 June (A-numbers) and 7 October 1999 (B-numbers) from the deepest part in the lake. 
growth rate, $g_{\mathrm{j}}\left(\mathrm{day}^{-1}\right)$, the specific rate of mass increase during the period from neonate to maturity: $g_{\mathrm{j}}=\left[\ln \left(M_{\mathrm{m}} / M_{\mathrm{n}}\right)\right] / t$, where $M_{\mathrm{m}}$ and $M_{\mathrm{n}}$ are the masses (mg) of the mature and neonate Daphnia, respectively, and $t$ is the time from neonate $(<24 \mathrm{~h}$ old) to maturity (typically 5 or 6 days at $20^{\circ} \mathrm{C}$ ). In laboratory experiments, juvenile growth rate is highly correlated $\left(r^{2}=0.99\right)$ with life-table estimates of the instantaneous rate of increase for Daphnia populations, and therefore can be interpreted as a reasonable measure of fitness in an exponentially growing population (Lampert \& Trubetskova, 1996). For each clone, $g_{j}$ was measured for animals fed on a poor food diet containing S. obliquus grown under low-P conditions (C:P ratio of the culture: $>1000$ ), and on standard algae (C:P of culture 137). The P-limited chemostat had a $\mathrm{P}$ concentration in the medium of $2 \mu \mathrm{M}$, which is $4 \%$ of the $\mathrm{P}$ available in the standard culture and a little lower as the $2.7 \mu \mathrm{M}$ used by Boersma (2000). In both treatments, the amount of food was the same $\left(1 \mathrm{mg} \mathrm{C}^{-1}\right)$. For each clone, $g_{\mathrm{j}, \text { lim }}$ and $g_{\mathrm{j}, \text { not-lim }}$ were measured separately using replicate $150-\mathrm{ml}$ flow-through culture chambers that sustained food at $1 \mathrm{mg} \mathrm{C} 1^{-1}$, well in excess of growth-limiting concentrations. Since our system had a capacity of maximal 96 flow-through chambers, the whole experiment was replicated three times, using the second, fourth and sixth brood of the mothers as our experimental animals. Each run of the experiment contained 24 (clones) $\times 2$ (food quality) $\times 2$ (replicates $)=96$ experimental units. Two replicate chambers per treatment, each containing four to eight individuals, were used for each growth-rate measurement on each Daphnia clone.
Initial weights were determined in triplicate for each clone using a minimum of six neonates isolated at the time of the start of a growth trial. At the termination of a growth trial, all individuals in each chamber were isolated and weighed together to an accuracy of $0.1 \mu \mathrm{g}$. All weight measurements were made on animals dried for $24 \mathrm{~h}$ at $60{ }^{\circ} \mathrm{C}$ on a Metller micro-balance. In addition, from three randomly chosen individuals, the length of an animal was measured as the distance from the top of the eye to the base of the tail spine, using an ocular micrometer. From these animals we also counted the number of eggs. We did not determine the age at maturity because we stopped the experiment after 6.5 days. At that moment most animals had eggs in their brood pouch.

\section{Data analysis}

To investigate whether Daphnia clones from different depth strata in the sediment reacted different to food quality differences we analyzed juvenile growth rates $\left(g_{\mathrm{j}}\right)$, size at first clutch and number of eggs in the first clutch in a mixed ANOVA design with food quality and depth as fixed factors and clone as nested random factor within depth.

\section{Results}

Juvenile growth rate $g_{j}$ differed significantly between both food qualities (Table 2, Fig. 1). There was also a highly significant clone effect. The depth in the sediment from which the clones were isolated, however, did not influence juvenile growth rate, and there was no significant depth $\times$ food

Table 2. Three-way mixed design ANOVA with food quality and depth as fixed factors and clone as nested random factor within depth

\begin{tabular}{|c|c|c|c|c|c|c|c|c|c|c|}
\hline & \multirow[t]{2}{*}{$\mathrm{df}$} & \multicolumn{3}{|c|}{$\begin{array}{l}\text { Juvenile growth rate }\left(g_{j}\right) \\
n=286\end{array}$} & \multicolumn{3}{|c|}{$\begin{array}{l}\text { Size first clutch } \\
n=293\end{array}$} & \multicolumn{3}{|c|}{$\begin{array}{l}\text { Size at maturity } \\
n=293\end{array}$} \\
\hline & & MS & $F$ & $p$ & MS & $F$ & $p$ & MS & $F$ & $p$ \\
\hline Clone & 18 & 0.011 & 4.533 & 0.000 & 10.038 & 7.580 & 0.000 & 713.991 & 14.279 & 0.000 \\
\hline Depth & 5 & 0.006 & 0.517 & 0.760 & 11.953 & 1.191 & 0.353 & 865.546 & 1.212 & 0.343 \\
\hline Food & 1 & 0.033 & 11.810 & 0.003 & 82.309 & 23.713 & 0.000 & 4054.422 & 39.853 & 0.000 \\
\hline Clone $\times$ food & 18 & 0.003 & 1.141 & 0.314 & 3.471 & 2.621 & 0.000 & 101.735 & 2.035 & 0.009 \\
\hline Depth $\times$ food & 5 & 0.006 & 2.224 & 0.097 & 1.407 & 0.405 & 0.839 & 77.646 & 0.763 & 0.588 \\
\hline
\end{tabular}

Significant effects are indicated in bold. 

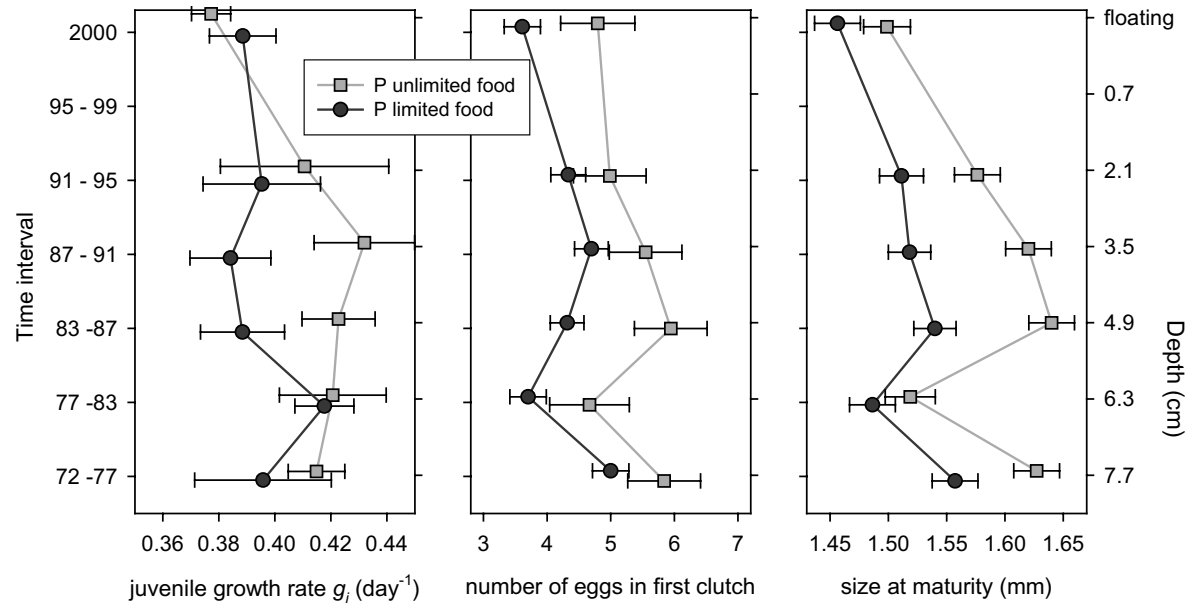

Figure 1. Mean values of three life history traits (juvenile growth rate, number of eggs in the first clutch and size at maturity), derived from the flow through experiment, for clones isolated from different depths of Greifensee sediment (see Table 1 for depth codes) at P-unlimited and P-limited food. Error bars indicate $95 \%$ confidence limits of the mean.

quality interaction. The number of eggs in the first clutch and the size at maturity showed the same pattern in their reaction to different food qualities (Table 2, Fig. 1). For both traits, there was a significant clone effect as well a significant effect of food quality. Animals grown on P-limited food were smaller and had fewer eggs. There was a significant clone $\times$ food quality interaction effect, but we found no significant interaction between depth and food quality (Table 2).

\section{Discussion}

Our results show clear differences in all measured life history traits between the P-limited and Punlimited food. Additionally we found significant clone effects as well as clone $\times$ food quality effects (Table 2, Fig. 1). However, we did not find the significant depth $\times$ food quality interaction as predicted by the hypothesis of adaptive microevolution. This means that the variation between clones is not structured along a depth gradient in the sediment from which they came.

Genetic analysis of these and additional D. galeata clones from Lake Greifensee sediment showed that the frequency of the Pgm-F allele significantly increased and that of $P g m-S$ decreased during the last 35 years (Keller, unpub- lished data). This indicates that the genetic composition of the D. galeata population in Lake Greifensee changed during the last 35 years. This is also the time frame during which the phosphorus concentration lowered dramatically in this lake. Our results are similar with those of Weider et al. (1997) who studied the Daphnia galeata population of Lake Constance. Similar to Lake Greifensee, D. hyalina, D. galeata and their interspecific hybrid coexists in Lake Constance. Analogous to what we found in Lake Greifensee Weider et al. (1997) also observed only D. galeata to hatch from the sediment. Weider et al. (1997) also observed a shift in allele frequencies with sediment depth. They used the same enzymes as we used and report a reduction in the frequency of the Pgm-S allele (Weider et al., 1997), the same allele for which we observed a reduction in frequency in Lake Greifensee. Both lakes underwent a phase of oligotrophication during the last 30 years. It is striking that the shifts are similar for the same taxon and same locus in both lakes. However, there are remarkable differences. The maximal phosphorus levels in Lake Constance were around $95 \mu \mathrm{g} \mathrm{l}^{-1}$ in the seventies, which is roughly the same level as where Lake Greifensee is now after a reduction from $600 \mu \mathrm{g} \mathrm{l}^{-1}$ in 1970 . This indicates that, although the process of oligotrophication occurred in both lakes, it can not be concluded that there is a direct causal relation between the 
reduction in P-loading and the changes in the $P g m-S$ allele frequency.

The selection pressure on adapting to $\mathrm{P}$ limitation might not have been high enough in Lake Greifensee where $\mathrm{P}$ levels, despite the strong reduction, are still a lot higher than for example in Lake Constance. Probably evidence for adaptive micro-evolution for the adaptation to P-limitation could be found in a lake like Lake Constance, especially since adaptive micro-evolution for the resistance to cyanobacteria already has been demonstrated for this lake (Hairston et al., 1999, 2001).

A problem during our experiment was that our P-limited algae managed to take up $\mathrm{P}$ from the lake water, making them a lot less P-limited than planned. The final C:P ratio in our experiment for the P-limited algae fluctuated between 180 and 420 with a mean of 223 . The C:P ratio of the unlimited algae was 134. Brett et al. (2000) stated in a literature overview that the true critical threshold for Daphnia lies between 225 and 375. This means that the daphnids in our flow through experiment were probably not $\mathrm{P}$ limited all the time.

Nevertheless, the P-limited algae significantly influenced all measured traits compared to the nonlimited algae. But since clones isolated from different depth showed the same reaction to these bad food conditions our result do not support the hypothesis of adaptive micro-evolution for the tolerance to P-limited food stress in Lake Greifensee.

\section{Acknowledgements}

The authors want to thank Christine Dambone for help in the laboratory and Hans Ruedi Bürgi, Richard Illi and Sven Schalla for support in the field and Luc De Meester for valuable comments and critical remarks on an earlier version of this paper. This research was supported by a Swiss Science Foundation grant no 31-65003.01 to PS.

\section{References}

Bloesch, J., H. Bührer, P. Bossard, H. R. Bürgi \& R. Müller, 1997. Lake oligotrophication due to external phosphorus load reduction in Swiss Lakes. Lakes Reservation Research and Management 2: 738-742.

Boersma, M., 2000. The nutritional quality of P-limited algae for Daphnia. Limnology and Oceanography 45: 1157-1161.
Brett, M. T., D. C. Muller Navarra \& S. K. Park, 2000. Empirical analysis of the effect of phosphorus limitation on algal food quality for freshwater zooplankton. Limnology and Oceanography 45: 1564-1575.

Bürgi, H., H. Bührer \& B. Keller, 2003. Long-term changes in functional properties and biodiversity of plankton in Lake Greifensee (Switzerland) in response to phosphorus reduction. Aquatic Ecosystem Health and Management 6: 147158.

Cousyn, C., L. De Meester, J. K. Colbourne, L. Brendonck, D. Verschuren \& F. Volckaert, 2001. Rapid local adaptation of zooplankton behavior to changes in predation pressure in absence of neutral genetic changes. Proceedings of the National Academy of Sciences of the United States of America 98: 6256-6260.

De Stasio, B. T., Jr., 1989. The seed bank of a freshwater crustacean: copepodology for the plant ecologist. Ecology 70: 1377-1389.

Duffy, M. A., L. J. Perry, C. M. Kearns, L. J. Weider \& N. G. Hairston, 2000. Paleogenetic evidence for a past invasion of Onondaga Lake, New York, by exotic Daphnia curvirostris using mtDNA from dormant eggs. Limnology and Oceanography 45: 1409-1414.

Duigan, C. A. \& H. H. Birks, 2000. The late-glacial and earlyHolocene palaeoecology of cladoceran microfossil assemblages at Krakenes, western Norway, with a quantitative reconstruction of temperature changes. Journal of Paleolimnology 23: 67-76.

Frey, D. G., 1969. The rationale of paleolimnology. Mitt Internat. Verein Limnol. 17: 7-18.

Frey, D. G., 1974. Paleolimnology. Mitt Internat Verein Limnol 20: 95-123.

Gießler, S., 1997. Analysis of reticulate relationships within the Daphnia longispina species complex. Allozyme phenotype and morphology. Journal of Evolutionary Biology 10: 87-105.

Guyer, O., 1910. Beiträge zur Biologie des Greifensees mit besonderer Berücksichtigung der Saisonsvariation von Ceratium hirundinella. Ph.D. Thesis, ETH, Zürich, 96 pp.

Hairston, N. G. \& C. E. Cáceres, 1996. Distribution of crustacean diapause: micro- and macroevolutionary pattern and process. Hydrobiologia 320: 27-44.

Hairston, N. G., C. L. Holtmeier, W. Lampert, L. J. Weider, D. M. Post, J. M. Fischer, C. E. Caceres, J. A. Fox \& U. Gaedke, 2001. Natural selection for grazer resistance to toxic cyanobacteria: evolution of phenotypic plasticity? Evolution 55: 2203-2214.

Hairston, N. G., W. Lampert, C. E. Caceres, C. L. Holtmeier, L. J. Weider, U. Gaedke, J. M. Fischer, J. A. Fox \& D. M. Post, 1999. Lake ecosystems - rapid evolution revealed by dormant eggs. Nature 401: 446.

Hairston, N. G., R. A. Vanbrunt, C. M. Kearns \& D. R. Engstrom, 1995. Age and survivorship of diapausing eggs in a sediment egg bank. Ecology 76: 1706-1711.

Hebert, P. D. N. \& M. J. Beaton, 1989. Methodologies for Allozyme Analysis Using Cellulose Acetate Electrophoresis. Helena Laboratories Beaumont, Texas, 32 pp.

Hofmann, W., 1991. The late-glacial/holocene Bosmina (Eubosmina) fauna of Lake Constance (Untersee) (F.R.G.): traces of introgressive hybridization. Hydrobiologia 225: 81-85. 
Hofmann, W., 1998. The response of Bosmina (Eubosmina) to eutophication of Upper Lake Constance: the subfossil record. Arch. Hydrobiol. Beih. Ergebn. Limnol. 53: 275-283.

Jankowski, T., 2002. From diapause to sexual reproduction: evolutionary ecology of the Daphnia hybrid complex from Lake Constance. Ph.D. Thesis, Universität Konstanz, Konstanz, 106 pp.

Jeppesen, E., P. Leavitt, L. De Meester \& J. P. Jensen, 2001. Functional ecology and palaeolimnology: using cladoceran remains to reconstruct anthropogenic impact. Trends in Ecology and Evolution 16: 191-198.

Keller, B., H. R. Bürgi, M. Sturm \& P. Spaak, 2002. Ephippia and Daphnia abundances under changing trophic conditions. Verh. Internat. Verein. Limnol. 28: 851-855.

Lampert, W. \& I. Trubetskova, 1996. Juvenile growth rate as a measure of fitness in Daphnia. Functional Ecology 10: 631-635.

Limburg, P. A. \& L. J. Weider, 2002. 'Ancient' DNA in the resting egg bank of a microcrustacean can serve as a palaeolimnological database. Proceedings of the Royal Society of London Series B-Biological Science 269: 281-287.

Mühlethaler, E., G. Gelpke, S. Schneider \& K. König Urmi, 1993. Der Greifensee: eine Dokumentation. Verband zum Schutze des Greifensees Uster, Egg, 72 pp.

Plath, K. \& M. Boersma, 2001. Mineral limitation of zooplankton: Stoichiometric constraints and optimal foraging. Ecology 82: 1260-1269.
Ruggiu, D., G. Morabito, P. Panzani \& A. Pugnetti, 1998. Trends and relations among basic phytoplankton characteristics in the course of the long-term oligotrophication of Lake Maggiore (Italy). Hydrobiologia 370: 243257.

Spaak, P., L. Eggenschwiler \& H. Bürgi, 2001. Genetic variation and clonal differentiation in the Daphnia population of the Greifensee, a pre-alpine Swiss lake. Verh. Internat. Verein. Limnol. 27: 1919-1923.

Sterner, R. W., D. D. Hagemeier \& W. L. Smith, 1993. Phytoplankton nutrient limitation and food quality for Daphnia. Limnology and Oceanography 38: $857-$ 871.

van der Molen, D. T., R. Portiele, P. C. M. Boers \& L. Lijklema, 1998. Changes in sediment phosphorus as a result of euthrophication and oligotrophication in Lake Veluwe, The Netherlands. Water Resesrch 32: 3281-3288.

Weider, L. J., W. Lampert, M. Wessels, J. K. Colbourne \& P. Limburg, 1997. Long-term genetic shifts in a microcrustacean egg bank associated with anthropogenic changes in the Lake Constance ecosystem. Proceedings of the Royal Society of London Series B-Biological Science 264: 16131618.

Wolf, H. G. \& M. A. Mort, 1986. Interspecific hybridization underlies phenotypic variability in Daphnia populations. Oecologia 68: 507-511. 